\title{
Investigating the implementation of potential strategies for enhancing urban mobility and a city logistics system on the island of Corfu
}

\author{
M. Morfoulaki ${ }^{1}$, K. Kotoula ${ }^{1}$, G. Mirovali ${ }^{1}$, K. Chrysostomou ${ }^{1}$, \\ A. Stathacopoulos ${ }^{1} \&$ A. Batsoulis ${ }^{2}$ \\ ${ }^{1}$ Hellenic Institute of Transport/Centre for Research and \\ Technology Hellas (HIT/CERTH), Greece \\ ${ }^{2}$ Cruise Department, PFSO, Corfu Port Authority S.A., Greece
}

\begin{abstract}
The aim of this paper is to identify potential strategies for establishing more sustainable transport systems, in the island of Corfu, Greece. Thus, it investigates the implementation of "intermediate" and "flexible" transport and logistics schemes, operated by eco-friendly vehicles, allowing Corfu Island to achieve high standards of energy efficiency and environmental quality. With an ultimate scope to achieve remarkable modal shift from private transport to eco and energy efficient sustainable services and significant rationalization of freight delivery services, the suggested strategies aim to achieve: reduction of private traffic, improvement of passengers' local mobility, rationalization and optimization of freight distribution on the island. Interviews with people working in the transport related field are utilized as the main research instrument and shed light on the needs and requirements of a reorganized transport system for both passengers and goods in the island. The investigation conducted, shows that the island needs a reduction of car use, improvement of public transport services and logistic services optimization. Therefore, three potential measures are proposed and further analyzed.
\end{abstract}

Keywords: city logistics, urban mobility, public transport services. 


\section{Introduction}

Enoch and Warren [1] have pointed out that islands are case studies of great interest as they effectively function as 'small-scale spatial laboratories where theories can be tested'. Many researchers have come to the conclusion, that islands concentrate a serious of economic, social, cultural, geographic and environmental characteristics which distinguish them from larger countries [2-4]. Such characteristics are demographic and economic factors, remoteness, size, seasonality due to touristic flows etc. However, Gakenheimer [5], has highlighted that the islands' main disadvantage is the fact that they face the same problems with developed countries, but with less time, experience and financial resources.

Regarding mobility related issues for both passengers and freight distribution, islands have to face among others difficult situations related to the steep increase of private car ownership resulting to traffic congestion and environmental problems, lack of adequate infrastructures, accessibility difficulties and lack of good transport links in order to reach remote regions. All the above, affect a region's competitiveness and prosperity negatively as its sustainable growth becomes further complicated.

Corfu is an island of Greece presenting an intense touristic character, thus characterized as an area with strong and seasonal demand variations both for freight and for passengers' transportation. Direct effects of this in combination with the fact that there is not any specific Sustainable Urban Mobility Plan (SUMP) for the city, are the subsequent growing problems, such as congestion, environmental pollution, energy loss and increased travel times especially during the summer period.

This paper proposes potential strategies for establishing more sustainable transport systems and mobility patterns, in the island of Corfu. Thus, it investigates the implementation of "intermediate" and "flexible" transport and logistics schemes, operated by eco-friendly vehicles and integrated in the broader context of mobility measures, allowing Corfu Island to achieve high standards of energy efficiency and environmental quality. A discussion is followed on the benefits that can be drawn from the adoption of the strategies for various target groups (tourists, local community etc.).

\section{Methodology}

For the identification of the potential measures to be implemented in order to enhance both the transport and the freight distribution system in the island, the methodological approach followed includes a series of actions (Figure 1):

\section{- Assessment of the existing situation in the city}

Before proposing any kind of measure in order to enhance sustainable urban mobility, it is necessary to evaluate the local transportation environment. This entails public transport operators as well as possible intermodal services, infrastructures and other characteristics. Likewise, an evaluation of the existing freight distribution system precedes before proposing any kind of measure for the 
enhancement of the city's urban logistics. The assessment of the above is based mainly on attitudes and beliefs arisen from interviews of those working in the transport related field.

- Identification and prioritization of the targets and goals the city should achieve The analysis of the current transportation and urban logistics system in the island results to specific goals and targets that the city should achieve. The goals are then ranked taking into account the real needs of the city as well as the opinions and priorities of the city authorities.

\section{- Identification of potential strategies for implementation}

Interviews with transport operators, representatives of the Association of transporters and the Corfu Port Authority, leads to a sound understanding of the changes should be made, in order basic needs and requirements to be covered. Thus, three measures are proposed.

\section{- Ex-ante assessment of the proposed measures}

The three proposed measures are ex- ante assessed in order to ensure that they serve the main goals and targets of the island, based on relevance, efficiency, effectiveness, utility and sustainability.

- Main results

Following the ex-ante assessment of the proposed measures, a presentation of the benefits and the expected results is discussed and further analyzed.

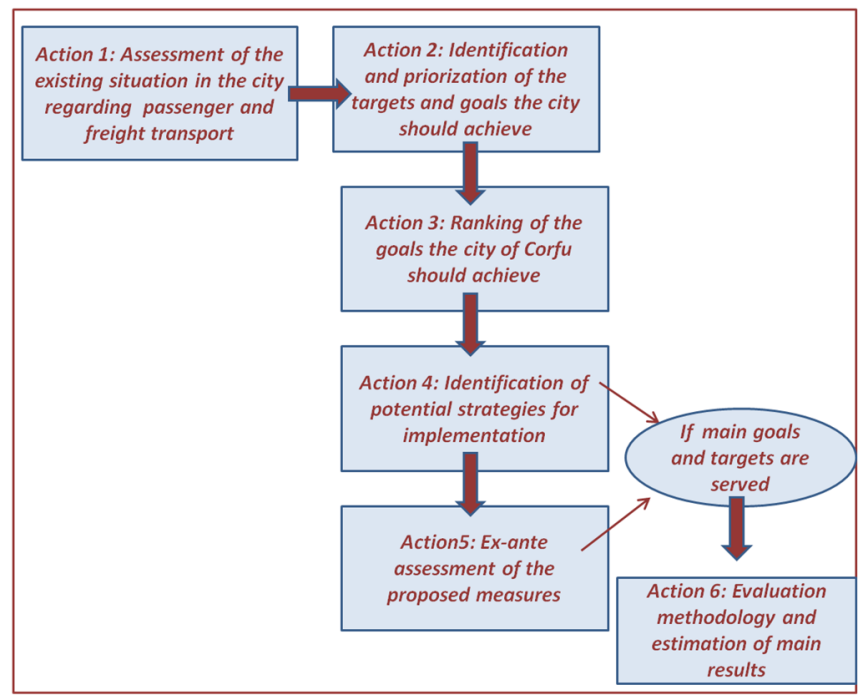

Figure 1: Identification of potential measures for implementation. 


\section{Case study}

\subsection{Study area}

Corfu is an island, located in the North Ionian Sea in Greece. It has a population of close to 102,000 residents and a surface of $614 \mathrm{~km}^{2}$. As the last number indicates, Corfu belongs among the most densely populated islands in the Mediterranean. It is also one of the most popular touristic destinations of the country. The island's economy is mainly based on tourism. The evolution of tourism on the island has been greatly facilitated by Corfu's good connectivity (by air, sea and road) at national and international level [6].

The increase of car ownership during the last decades in combination with the increase in tourism at the island, led to the creation of intense traffic problems as the existing road network and the related infrastructure are not sufficient to cover the ever increasing traffic. The lack of parking together with the concentration of many activities in the wider study area (administrative, commercial and recreational), further burden the congestion at the whole or at parts of Corfu's road network.

The problem further worsens as a result of badly organized city logistics (in terms of insufficient infrastructure - loading and unloading parking lots, restricted time plan for goods delivery and in terms of routing optimization and optimized loading factors). The lack of effective policy schemes and managing structures of urban freight flows seems to intensify all negative impacts related to energy consumption, air pollutants production, noise, visual disturbance. The above mentioned reveals the compelling need for better organization and for optimal management of the supply chain; best practices can be the base for this reorganization that will be in line with the European vision of sustainable development.

\subsection{Assessment of the existing situation in the island}

Regarding Corfu's public transport system there are two operators serving the urban and interurban routes of the island respectively. Interviews with representatives of both urban and interurban public transport operators led to some useful conclusions, regarding the system's functionality and needs have to be covered:

As for the urban public transport system:

- The island has special characteristics regarding seasonality and high variation on trip demand as passengers' flow ranges from 520,000 during the winter to $1,800,000$ during the summer period.

- Passengers' flow has increased both in summer and winter season during the last years, mainly due to the economic crisis the country faces, as well as the improvement of the services' quality the company provides.

- Current routes seem to cover most of the travellers' needs, but often problems related to the reliability of the provided services occur mostly 
due to traffic congestion and illegal parking of private and freight vehicles.

- The use of eco-friendly buses is not popular.

- What seems to be missing from the urban public transport system is a circular service around the city centre oriented to cover visitors' needs.

As for the interurban public transport system:

- Passengers' flow ranges from 59,000 during the winter to 270,000 during the summer period.

- Routes carried out cover most of the travellers' needs at a large degree.

- The use of new technologies (i.e. mobility planning services, information provision, fleet tracking) and eco-friendly vehicles is not popular.

- A missing point of the interurban public transport system is the lack of a line directly connecting touristic areas located out of the city of Corfu.

Regarding the freight distribution services:

- There is no properly organized system, serving exclusively urban freight transport. This affects the city's functionality negatively, as freight transport is responsible for a substantial portion of traffic flow in the road network.

- Freight distribution services are provided by old vehicles. The need for replacement by new environmentally friendly ones is obvious.

- There is complete lack of loading/unloading places. This results in an increase of the number of vehicle $\mathrm{km}$ travelled daily, as transporters can't find a free place to park and inevitably in energy consumption, traffic congestion and increased air pollution.

- Another problem identified is the fact that products that need to get delivered within the city centre are not concentrated in a particular van but share a large number of vehicles, partly loaded. So, while the city's needs could be accommodated by five trucks, more than twenty are being used [7].

\subsection{Identification and prioritization of the targets the city should achieve}

The city situation assessment, stressed out some of the important characteristics regarding both the passenger and the freight transportation system and led straight to the main targets the city of Corfu should achieve in order to promote urban sustainable mobility by strengthening the profile of public transport and freight distribution system in the island. The identified goals are:

- Reduction in congestion due to freight services in the city centre.

- Reduction in transport and freight related emissions.

- Increase of public transport use for tourism.

- Optimization of city centre logistics vkm due to appropriate fleet management.

- Optimization of passenger transport vkm due to appropriate management of public transport fleet.

- Uptake of clean transport vehicles. 
- Significant increase of touristic areas directly linked with public transport lines.

A prioritization procedure follows categorizing the above goals in High, Medium and Low Level Objectives and is presented in Table 1 below.

Table 1: Prioritization of main goals to be achieved.

\begin{tabular}{|l|c|c|c|}
\hline \multicolumn{2}{|c|}{ Priorization of main goals to be achieved } & \multicolumn{3}{c|}{ Objective's level } \\
\cline { 2 - 4 } & High & Medium & Low \\
\hline $\begin{array}{l}\text { Reduction in congestion due to logistic services in the } \\
\text { city centre. }\end{array}$ & $\sqrt{ }$ & & \\
\hline Reduction in transport and logistics related emissions. & $\sqrt{ }$ & & \\
\hline Increase in the use of public transport mode for tourism. & $\sqrt{ }$ & & \\
\hline $\begin{array}{l}\text { Optimization of the vkm used for city centre logistics due } \\
\text { to appropriate management of fleet and cargo. }\end{array}$ & $\sqrt{ }$ & & \\
\hline $\begin{array}{l}\text { Optimization of the vkm used for passenger transport due } \\
\text { to appropriate management of public transport fleet. }\end{array}$ & & $\sqrt{ }$ & \\
\hline Uptake of clean transport vehicles. & & $\sqrt{ }$ & \\
\hline $\begin{array}{l}\text { Significant increase in the touristic areas of Corfu that are } \\
\text { directly linked with public transport lines. }\end{array}$ & $\sqrt{ }$ & & \\
\hline
\end{tabular}

\subsection{Proposing potential measures for implementation}

Based on the city's targets prioritization, three potential measures are proposed and further analyzed below. The two of them are passenger services fully compatible with the island's needs for more touristic-oriented services in the urban and interurban area, while the third one covers the need for optimization of the city logistic system.

\subsubsection{The 'City of Corfu Tour' service}

The first measure called 'City of Corfu Tour' service refers to a circular route starting and ending at the port of the island, making a series of stops in places of interest both for visitors and for residents. Its total length is $6.0 \mathrm{~km}$ (Figure 2a) and the trip duration is estimated to 25 minutes. The service can be provided in a frequency of 20-30 minutes with itineraries staring early morning till late in the evening. The daily total number of trips provided is estimated to 26 ( 2 per hour from 9:00-22:00pm) and refers to the summer period starting from June until the end of August.

For the implementation of this service the use of environmentally friendly vehicles should be considered, such as electric mini buses. From an environmental perspective it is important to note that, the use of electric traction is possible in this area of the island as the morphology of the terrain does not present large slopes. 


\subsubsection{The 'Corfu North and West Visit' service}

The second service is a suburban service covering the North and West side of the island and connecting touristic areas located far away from the city. These areas are very famous for their beaches. In such touristic areas, the existing public transport services fail to serve tourists' needs as these locations are far away from the city centre, the number of itineraries cannot respond to the passenger flow, and there are no correspondence routes to connect them. To cover this gap, the service 'Corfu North and West Visit' is proposed. Figures $2 b$ and $2 c$ depict the proposed routes.

The Northern route connects the costal destinations of Sidari and Kassiopi, two of the most famous beaches of the island. The distance from Corfu city to Sidari is approximately $36 \mathrm{~km}$ and the total trip time is about an hour. The length of the proposed route from Sidari to Kassiopi is $30 \mathrm{~km}$ and the trip duration is estimated to $45 \mathrm{~min}$. The daily total number of trips is estimated to $6(1$ per two hours including the route from Kassiopi back to Sidari, starting from 9:00-19:00am) and refers to the summer period starting from June until the end of August.

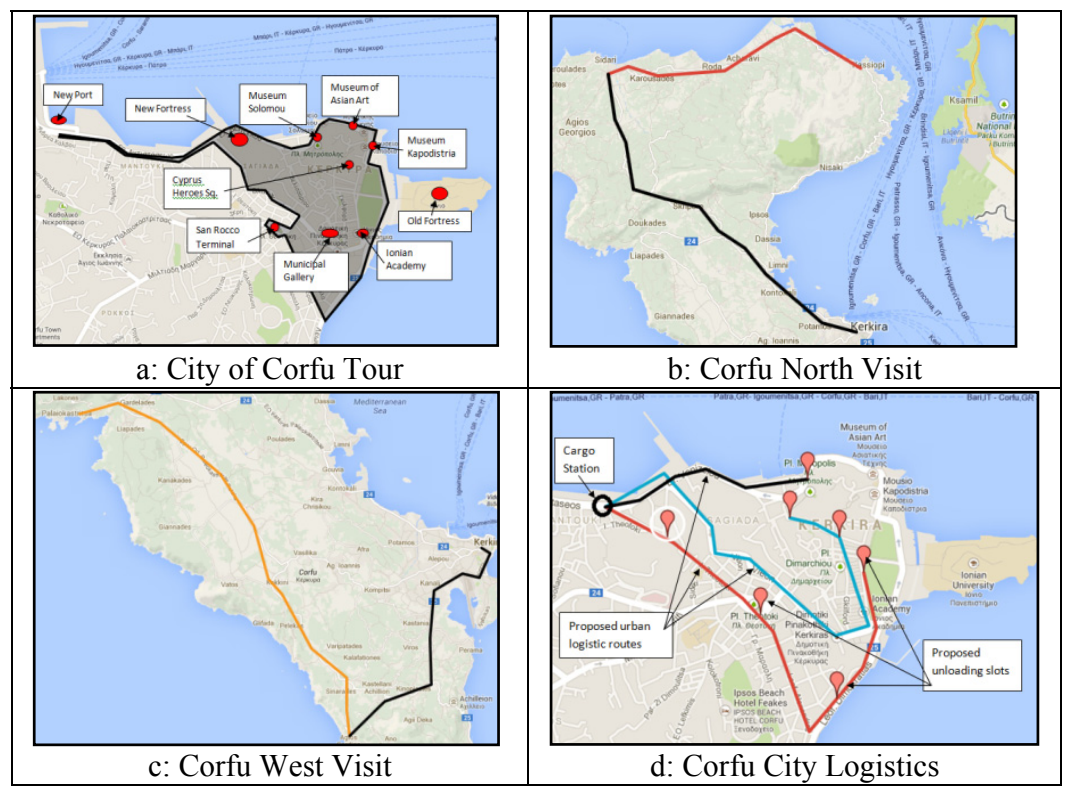

Figure 2: The proposed services.

Respectively, the West route connects the coastal destinations of Agios Gordis and Paleokastritsa, also famous beaches of the island. The distance from Corfu city to Agios Gordis is approximately $16 \mathrm{~km}$ and the total trip time is about half an hour. The length of the proposed route from Agios Gordis to Paleokastritsa is $25 \mathrm{~km}$ and the trip duration is estimated to $45 \mathrm{~min}$. The daily total number of provided trips is estimated to 6 ( 1 per two hours including the route from Paleokastritsa back to Agios Gordis, starting from 9:00-19:00am) and refers to the 
summer period starting from June until the end of August. For the implementation of this service the use of environmentally friendly vehicles should be taken into account. A good solution would be the use of electric mini buses, as there is no gas supply in the island yet.

\subsubsection{The 'Corfu City Logistics' service}

The proposed 'Corfu City Logistics' service, will allow the optimization of deliveries and especially of the "last mile" cargo transportation. More specifically, this service deals with the planning and creation of a central consolidation centre near the port of Corfu, where all transport companies concentrate their cargo. After the collection of goods, a cargo consolidation will follow sorting products and allocating them in vehicles (mini vans). Each van will run a specific route, park in specific loading/unloading places in the pedestrian and restricted zones and finally distribute cargo serving all professionals' needs safely and on time. A proposed scheme of this procedure is depicted in Figure 2d.

The consolidation centre can be developed with the cooperation of private and public authorities and could be a solution that would provide important transportation benefits. Special attention should also be given to the future replacement of the fleet with new technology ecofriendly vehicles since a great percentage of the current fleet which serves the city is very old. For the optimization of the "last mile" distribution, electrical mini vans are a good solution to be used, contributing to a reduction of $\mathrm{CO}_{2}$ pollutants.

\subsection{Ex-ante assessment of the proposed measures}

The three proposed measures can ex-ante be assessed in order to ensure that they serve the main goals of the island. The assessment (Table 2), will be realized based on:

Relevance: To what extent is the measure relevant to the local needs and priorities? Efficiency: How (easily or not) will the resources turn into outputs or results? Effectiveness: How much will the measures help Corfu achieve its specific goals? Utility: Will the measures have an impact on population in relation to their needs? Sustainability: To what extent will the benefits last after the measures' implementation?

\subsection{Main results}

The main results of the proposed measures can be calculated after the first month of the service execution and can be described using the following indicators:

(\%) Reduction of the $\mathrm{v} / \mathrm{c}$ ratio of the main axis during the peak hours.

(\%) Increase of the Average Speed in the main city axis.

(\%) Increase of the Urban and Interurban public transport Share.

(\%) Reduction of city logistics vkm and of the number of vans entering the city.

(\%) Increase of the occupancy rate of the vans entering the city centre. 
Table 2: Ex-ante evaluation for the proposed measures.

\begin{tabular}{|c|c|}
\hline \multicolumn{2}{|r|}{ The 'City of Corfu Tour' } \\
\hline Relevance & $\begin{array}{l}\text { Answers to the local needs for attracting more tourists to the PuT } \\
\text { system }\end{array}$ \\
\hline Efficiency & $\begin{array}{l}\text { Can be easily implemented as the PuT operator has already available the } \\
\text { needed fleet and can give positive results from the first day of its } \\
\text { operation }\end{array}$ \\
\hline Effectiveness & $\begin{array}{l}\text { Will contribute to the improvement of traffic conditions, the } \\
\text { minimization of air pollution, enhancing also the energy savings and } \\
\text { modal share of PuT }\end{array}$ \\
\hline Utility & $\begin{array}{l}\text { Will improve the residents' life by improving traffic conditions and } \\
\text { quality of air serving the tourists' needs for sustainable, reliable and } \\
\text { easy city tour }\end{array}$ \\
\hline Sustainability & $\begin{array}{l}\text { Will be supported and adopted by the urban PuT Authority and it will be } \\
\text { integrated to its work schedule. Thus, the service will be long-lasted }\end{array}$ \\
\hline \multicolumn{2}{|r|}{ 'Corfu North/West visit' } \\
\hline Relevance & $\begin{array}{l}\text { Answers to the local needs for attracting more tourists to the interurban } \\
\text { PuT system, connecting also directly places and beaches of interest }\end{array}$ \\
\hline Efficiency & $\begin{array}{l}\text { Can be easily implemented as the PuT operator has already available the } \\
\text { needed fleet and can give positive results from the first day of its } \\
\text { operation }\end{array}$ \\
\hline Effectiveness & $\begin{array}{l}\text { Will contribute to the improvement of traffic conditions, the } \\
\text { minimization of air pollution, the increase of energy savings and the } \\
\text { modal share of PuT }\end{array}$ \\
\hline Utility & $\begin{array}{l}\text { Will improve all residents' life by improving the traffic conditions, the } \\
\text { connectivity of the places and the environmental conditions. It will also } \\
\text { serve the tourists' needs for sustainable, reliable and easy access to the } \\
\text { most popular beaches and touristic destinations in the interurban area }\end{array}$ \\
\hline Sustainability & $\begin{array}{l}\text { Will be supported and adopted by the interurban PuT Authority and } \\
\text { integrated to its schedule }\end{array}$ \\
\hline \multicolumn{2}{|r|}{ 'Corfu City Logistis' } \\
\hline Relevance & Answers to the local needs for supply chain optimization \\
\hline Efficiency & $\begin{array}{l}\text { Requires cooperation between transporters, the construction of a } \\
\text { consolidation center, the development of a new private/public company } \\
\text { that will operate it, new business models, agreements and probably a } \\
\text { number of more ecofriendly vehicles. All the above pre require } \\
\text { investment funds and examination of legal and business obstacles }\end{array}$ \\
\hline Effectiveness & $\begin{array}{l}\text { Will contribute to the optimization of the city logistics services, upgrade } \\
\text { of the customers satisfaction and contribute to the improvement of } \\
\text { traffic conditions within the city center }\end{array}$ \\
\hline Utility & $\begin{array}{l}\text { Will improve the residents' life by improving traffic conditions and air } \\
\text { quality serving at the same time the shop keepers' needs }\end{array}$ \\
\hline Sustainability & $\begin{array}{l}\text { Requires lots of work, cooperation and funds. The consolidation center, } \\
\text { will soon become the heart of the logistic services in the island, and due } \\
\text { to the positive effects that it will bring to the businesses and the local } \\
\text { society, its sustainability can be taken for granted }\end{array}$ \\
\hline
\end{tabular}

Moreover, an estimation of the results in terms of reduced environmental impact and energy savings is presented in the Table 3, considering the below assumptions: 
'City of Corfu Tour Service': The initial assessment concerns 2,392 in total itineraries (of $6 \mathrm{~km}$ ) that will run throughout the duration of the summer season. These services will be performed by small electric buses (20 seats). For an occupancy rate of $70 \%$ (14 seats/itinerary) the total number of transported passengers is estimated at 33,488 . If these passengers use private vehicles for their travels and the average vehicle occupancy is estimated at $60 \%$, then the total $\mathrm{km}$ traveled for the same itinerary is about $66,900 \mathrm{~km}$. Regarding CO2 emissions, it is noted that for the electric buses these are zero, while in the case of private vehicles and for an average speed of around $25 \mathrm{~km} / \mathrm{h}$, it is calculated according to the software COPERT (180gr/km/vehicle) [8].

Table 3: Estimation of results in terms of reduced environmental impact.

\begin{tabular}{|c|c|c|c|}
\hline Service size & $\begin{array}{l}\text { City of Corfu } \\
\text { Tour }\end{array}$ & $\begin{array}{c}\text { Corfu North/West } \\
\text { Visit }\end{array}$ & $\begin{array}{c}\text { Corfu City Logistic } \\
\text { service }\end{array}$ \\
\hline Total run $(\mathrm{km})$ & 14,352 & 60,720 & Today: $\mathbf{2 5 , 2 0 0}$ \\
\hline Transported passengers & 33,488 & 33,120 & - \\
\hline Equivalent car km & 66,900 & 609,200 & $\mathbf{7 8 2 0}$ after/measure \\
\hline \multicolumn{4}{|l|}{ Environmental benefits } \\
\hline $\mathrm{CO}_{2}$ emissions (ton) & $\begin{array}{l}\text { Electric bus: } 0 \\
\text { local level }\end{array}$ & Diesel buses: $\mathbf{4 4 . 9 2}$ & Today : $\mathbf{7 . 0 5}$ \\
\hline $\mathrm{CO}_{2}$ emissions (ton) & $\begin{array}{l}\text { Vehicles: } \\
\mathbf{1 2 . 0 4} \\
\end{array}$ & Vehicles : 97.16 & Small diesel vans : $\mathbf{2 . 1 8}$ \\
\hline \multicolumn{4}{|l|}{ Energy savings } \\
\hline \multirow[t]{2}{*}{ Power consumption } & $\begin{array}{l}\text { Electric buses } \\
\mathbf{3 1 , 5 7 4 , 4 0 M J}\end{array}$ & $\begin{array}{l}\text { Diesel buses } \\
\mathbf{6 3 7 , 5 6 0} \mathbf{M J}\end{array}$ & $\begin{array}{l}\text { Today } \\
\mathbf{8 8 . 2 0} \text { MJ }\end{array}$ \\
\hline & $\begin{array}{l}\text { Vehicles } \\
\mathbf{2 3 2 , 8 1 2} \text { MJ } \\
\end{array}$ & $\begin{array}{l}\text { Vehicles } \\
\mathbf{1 , 7 0 0 , 1 6 0} \text { MJ }\end{array}$ & $\begin{array}{l}\text { Small diesel vans } \\
\text { 27.37MJ }\end{array}$ \\
\hline
\end{tabular}

'Corfu North/West Visit Service': The initial assessment concerns 1104 in total itineraries $(60 \mathrm{~km}$ distance for the North and $50 \mathrm{~km}$ for the West itinerary) that will run throughout the duration of the summer season. These services will be performed by conventional diesel buses (50 seats). For an occupancy rate of $60 \%$ (30 seats per itinerary) the total number of transported passengers is estimated at 33,120 . If these passengers use private vehicles for their travels and the average vehicle occupancy is estimated at $60 \%$ (three passengers per vehicle), then the total $\mathrm{km}$ traveled for the same itinerary is about $609,200 \mathrm{~km}$.

Regarding $\mathrm{CO}_{2}$ emissions, for conventional buses (diesel) and for an average speed of around $50 \mathrm{~km} / \mathrm{h}$ (within the interurban area) these are calculated at 44.92 ton according to the software COPERT (740 gr $/ \mathrm{km} / \mathrm{vehicle})$, while in the case of private vehicles the relevant number reaches 97.16 ton $(160 \mathrm{gr} / \mathrm{km} / \mathrm{vehicle})$.

'Corfu City Logistics Service': the initial assessment concerns 3 different routes of 2,3 , and $3,5 \mathrm{~km}$ respectively, covering the supply needs of the city centre. The starting point of these routes as mentioned above will be a consolidation centre located near the port. If each route is carried out 10 times during the day, then the total distance $\mathrm{km}$ covered per day is 85 , while for the whole summer season the total distance $\mathrm{km}$ covered is equal to $7820 \mathrm{~km}$. The relevant distance $\mathrm{km}$ covered daily by the 20 freight taxis, is equal to 280 according to the Transport 
Association representative's opinion, thus $25,200 \mathrm{~km}$ are covered during the summer period.

Regarding $\mathrm{CO}_{2}$ emissions, for small freight vans (diesel) and for an average speed of around $25 \mathrm{~km} / \mathrm{h}$ within the urban area, these are calculated according to the software COPERT ( $280 \mathrm{gr} / \mathrm{km} /$ vehicle).

\section{Conclusions}

The current work aims to achieve remarkable modal shift from private/individual transport to eco and energy efficient sustainable services and significant rationalization of freight delivery services, in the island of Corfu by suggesting specific measures leading to:

- The reduction of private traffic incoming flows from Corfu Port to the historic centre of the city by offering to both residents and tourists a circular route making a series of stops in places of interest.

- The improvement of all tourists' mobility by offering public transport services which connect directly remote places of the island famous for their beaches.

- The rationalization and optimization of freight distribution on the island, by offering freight consolidation on the mainland side (Corfu port area) and reduction of the freight trips reaching the centre of the city.

The proposed measures can cover in a degree the seasonal needs of the island in a sustainable way. However a central planning is needed engaging all interested authorities and operators who can offer a small piece in the puzzle that will make Corfu a more sustainable place for residents and tourists.

An open discussion between the operators and the main users of the network can bring into light many problems but also propose solutions, which may not be very easily implemented but can have many positive effects to the society such as: reduction of the $\mathrm{v} / \mathrm{c}$ ratio of the main axes during the peak hours, increase of the average speed in the main city axes, increase of the urban and interurban public transport share, increase of direct connected touristic places by Public Transport, reduction of city logistics vkm, reduction of the number of vans entering the city centre and increase of the occupancy rate of the vans entering the city centre.

\section{References}

[1] Enoch, M.P., Warren, J.P., Automobile use within selected island states, Transportation Research Part A 42, 1208-121, 2008

[2] Weisser, D., 2004. On the economics of electricity consumption in Small Island Developing States: a role for renewable energy technologies? Energy Policy 32, 127-140

[3] Lockhart, D.G., Drakakis-Smith, D., Schembri, J., 1993. The Development Process in Small Islands Developing States, Routledge, London

[4] Kakazu, H., Sustainable development of small island Economies, Westview Press, Oxford, UK, 1994 
[5] Gakenheimer, R., Urban mobility in the developing world, Transportation Research A 33, 671-699, 1999

[6] Morfoulaki, M., Kotoula, K., Identification and assessment of the current situation regarding the operation of passenger and freight transport in Corfu island - Regulatory framework for the operation of transport services, Deliverable D1, Technical consulting services to the Port of Corfu in order to explore the feasibility and transferability of the ELBA pilot services on Corfu Island at the framework of ELBA project, 2014

[7] Morfoulaki, M., Kotoula, K., Myrovali, G., Transferability evaluation of the ELBA pilot services on Corfu Island, Deliverable D2, Technical consulting services to the Port of Corfu in order to explore the feasibility and transferability of the ELBA pilot services on Corfu Island at the framework of ELBA project, 2014

[8] Gkatzoflias, D., Kouridis, C., Ntziachristos, L., Samaras, Z., COPERT 4, Computer programme to calculate emissions from road transport, Laboratory of applied thermodynamics mechanical engineering department, Aristotle University of Thessaloniki, Greece, 2007 